\title{
Efficacy of Second-line Chemotherapy in Patients With Sensitive Relapsed Small-cell Lung Cancer
}

\author{
KAZUSHIGE WAKUDA ${ }^{1}$, TAICHI MIYAWAKI ${ }^{1}$, ERIKO MIYAWAKI ${ }^{1}$, NOBUAKI MAMESAYA ${ }^{1}$, \\ TAKAHISA KAWAMURA ${ }^{1}$, HARUKI KOBAYASHI ${ }^{1}$, SHOTA OMORI $^{1}$, \\ KAZUHISA NAKASHIMA ${ }^{1}$, AKIRA ONO ${ }^{1}$, HIROTSUGU KENMOTSU ${ }^{1}$, TATEAKI NAITO $^{1}$, \\ HARUYASU MURAKAMI ${ }^{1}$, KEITA MORI $^{2}$, MASAHIRO ENDO $^{3}$ and TOSHIAKI TAKAHASHI ${ }^{1}$ \\ ${ }^{1}$ Division of Thoracic Oncology, Shizuoka Cancer Center, Nagaizumi, Japan; \\ ${ }^{2}$ Clinical Trial Coordination Office, Shizuoka Cancer Center, Nagaizumi, Japan; \\ ${ }^{3}$ Division of Diagnostic Radiology, Shizuoka Cancer Center, Nagaizumi, Japan
}

\begin{abstract}
Background/Aim: To evaluate treatment efficacy of cisplatin, etoposide, and irinotecan combined therapy (PEI), platinum-rechallenge chemotherapy (Pt-Re) and amrubicin monotherapy (AMR) for patients with sensitive relapsed small cell lung cancer (SCLC). Patients and Methods: We defined sensitive relapse as treatment-free interval (TFI) $\geq 90$ days. We retrospectively collected patients' data from medical records between September 2002 and December 2016. Patients with sensitive relapsed SCLC who received second-line chemotherapy were separated into those treated with PEI, with Pt-Re, or with AMR. Results: Seventy-one patients (16 PEI group, 27 Pt-Re group, and 28 AMR group) were assessable for efficacy. No significant differences in patient characteristics were found among the three groups. The median overall survival (MST) was 29.3 months in the PEI group, 24.6 months in the Pt-Re group, and 20.6 months in the AMR group ( $p=0.042)$. Conclusion: A significant difference was observed in the overall survival of patients treated with PEI, Pt-Re and AMR and the MST of PEI was the longest.
\end{abstract}

Lung cancer is the most common cause of cancer-related death. Small-cell lung cancer (SCLC) is one of the major histological types of lung cancer and strongly associated with

This article is freely accessible online.

Correspondence to: Kazushige Wakuda, Division of Thoracic Oncology, Shizuoka Cancer Center Hospital, 1007 Shimonagakubo, Nagaizumi-cho, Suntou-gun, Shizuoka 411-8777, Japan. Tel: +81 559895222, Fax: +81 559895634, e-mail: k.wakuda@scchr.jp

Key Words: Small-cell lung cancer, second-line chemotherapy, sensitive relapse, cisplatin etoposide and irinotecan, platinum rechallenge. smoking. Although the number of smokers is decreasing, SCLC still accounts for approximately $12 \%$ of lung cancers (1). About $80 \%$ of limited-disease patients and almost all patients with extended disease will develop disease relapse or progression after first-line treatment (2). Without secondline chemotherapy, the median survival time (MST) is 2 to 4 months (3).

The efficacy of second-line chemotherapy differs depending on the treatment-free interval (TFI), which is the time from the end of first-line treatment to progression. Patients with relapsed SCLC are thus conventionally separated into those with sensitive relapse and those with refractory relapse according to the TFI. It was shown that, in cases with refractory relapsed SCLC, second-line chemotherapy had lower efficacy than in sensitive relapsed SCLC $(1,4,5)$. In 2006, the results of a phase III trial comparing oral topotecan with best supportive care (BSC) were reported (6). The MST was 25.9 weeks for patients receiving topotecan and 13.9 weeks for those receiving $\mathrm{BSC}$ $(\mathrm{HR}=0.64 ; 95 \% \mathrm{CI}=0.45-0.90 ; p=0.0104)$. Thereafter, there was no drug showing efficacy compared with BSC. There is also still limited clinical evidence regarding second-line chemotherapy for patients with sensitive relapsed SCLC and, until recently, topotecan was the only drug available for the treatment of such patients.

In 1987, two studies showed the efficacy of retreatment with an induction regimen $(7,8)$. Although the induction regimens in these studies were CAV (cyclophosphamide, doxorubicin, vincristine) and CDE (cyclophosphamide, doxorubicin, etoposide), patients with sensitive relapsed SCLC have a good chance of responding to rechallenge chemotherapy. Based on these reports, several sets of guidelines recommend rechallenge chemotherapy for patients with sensitive relapsed SCLC. However, no phase III trial of rechallenge chemotherapy had been performed and there was almost no evidence regarding rechallenge chemotherapy. An 
Table I. Characteristics of sensitive relapse* of SCLC patients in the three groups.

\begin{tabular}{|c|c|c|c|c|}
\hline & $\begin{array}{l}\text { PEI group } \\
\quad(n=16)\end{array}$ & $\begin{array}{l}\text { Pt-Re group } \\
\quad(\mathrm{n}=27)\end{array}$ & $\begin{array}{l}\text { AMR group } \\
\quad(\mathrm{n}=28)\end{array}$ & $p$-Value \\
\hline $\begin{array}{l}\text { Age at second-line } \\
\text { chemotherapy (years) }\end{array}$ & & & & 0.598 \\
\hline Median & 62 & 66 & 64 & \\
\hline Range & $53-74$ & $51-73$ & $43-74$ & \\
\hline Gender, n (\%) & & & & 0.133 \\
\hline Male & $15(94 \%)$ & $19(70 \%)$ & $19(68 \%)$ & \\
\hline Female & $1(6 \%)$ & $8(30 \%)$ & $9(32 \%)$ & \\
\hline $\begin{array}{l}\text { PS at second-line } \\
\text { chemotherapy, } \mathrm{n}(\%)\end{array}$ & & & & 0.388 \\
\hline $0-1$ & $16(100 \%)$ & $24(89 \%)$ & $26(93 \%)$ & \\
\hline $2-4$ & $0(0 \%)$ & $3(11 \%)$ & $2(7 \%)$ & \\
\hline Smoking index & & & & 0.539 \\
\hline$<400$ & $16(100 \%)$ & $25(93 \%)$ & $26(93 \%)$ & \\
\hline$\geq 400$ & $0(0 \%)$ & $2(7 \%)$ & $2(7 \%)$ & \\
\hline $\begin{array}{l}\text { Disease extent at } \\
\text { diagnosis, } \mathrm{n}(\%)\end{array}$ & & & & 0.741 \\
\hline LD & $7(44 \%)$ & $12(44 \%)$ & $15(54 \%)$ & \\
\hline ED & $9(56 \%)$ & $15(56 \%)$ & $13(46 \%)$ & \\
\hline $\begin{array}{l}\text { Response to first-line } \\
\text { therapy, } \mathrm{n}(\%)\end{array}$ & & & & 0.438 \\
\hline $\mathrm{CR} / \mathrm{PR}$ & $16(100 \%)$ & $26(96 \%)$ & $28(100 \%)$ & \\
\hline SD & $0(0 \%)$ & $1(4 \%)$ & $0(0 \%)$ & \\
\hline $\begin{array}{l}\text { Treatment-free } \\
\text { interval (months) }\end{array}$ & & & & 0.177 \\
\hline Median & 146 & 201 & 147 & \\
\hline Range & $106-637$ & $94-1176$ & $90-361$ & \\
\hline
\end{tabular}

*Defined as TFI $\geq 90$ days. SCLC: Small-cell lung cancer; PEI: cisplatin, etoposide, and irinotecan combined therapy; Pt-Re: platinum rechallenge; AMR: amrubicin; PS: performance status; LD: limited disease; ED: extended disease; CR: complete response; PR: partial response; SD: stable disease; TFI: treatment-free interval.

exception to this is the finding that amrubicin showed response rates of $44 \%$ to $53 \%$ for patients with sensitive relapsed SCLC in two phase II trials $(9,10)$. In addition, in 2014, a phase III trial comparing amrubicin with topotecan was reported (11). However, in that trial, amrubicin did not improve survival compared with topotecan (MST was 7.5 months with amrubicin versus 7.8 months with topotecan, $\mathrm{HR}=0.880 ; p=0.170$ ).

A phase III trial comparing cisplatin, etoposide, and irinotecan combined therapy (PEI) with topotecan for patients with sensitive relapsed SCLC was reported in 2016 (JCOG 0605) (12). PEI significantly prolonged survival compared with topotecan (MST was 18.2 months with PEI versus 12.5 months with topotecan, $\mathrm{HR}=0.67 ; p=0.0079)$; as a result, PEI became the standard second-line chemotherapy for patients with sensitive relapsed SCLC. However, the treatment schedule of PEI is complicated, so it has rarely been applied in a clinical setting. Instead of PEI, platinum-
Table II. Response to second-line chemotherapy in the three groups.

\begin{tabular}{lccc}
\hline & $\begin{array}{c}\text { PEI group } \\
(\mathrm{n}=16)\end{array}$ & $\begin{array}{c}\text { Pt-Re group } \\
(\mathrm{n}=27)\end{array}$ & $\begin{array}{c}\text { AMR group } \\
(\mathrm{n}=28)\end{array}$ \\
\hline Response, $\mathrm{n}(\%)$ & & & \\
$\mathrm{CR}$ & $2(13 \%)$ & $1(4 \%)$ & $0(0 \%)$ \\
$\mathrm{PR}$ & $11(68 \%)$ & $12(44 \%)$ & $11(39 \%)$ \\
$\mathrm{SD}$ & $2(13 \%)$ & $7(26 \%)$ & $9(32 \%)$ \\
$\mathrm{PD}$ & $0(0 \%)$ & $4(15 \%)$ & $7(25 \%)$ \\
$\mathrm{NE}$ & $1(6 \%)$ & $3(11 \%)$ & $1(4 \%)$ \\
Overall response rate $(\%)$ & $81 \%$ & $48 \%$ & $39 \%$ \\
$p$-Value & 0.128 & & \\
\hline
\end{tabular}

PEI: Cisplatin, etoposide, and irinotecan combined therapy; Pt-Re: platinum rechallenge; AMR: amrubicin; CR: complete response; PR: partial response; SD: stable disease; PD: progressive disease; NE: not evaluable.

rechallenge chemotherapy (Pt-Re) or amrubicin monotherapy (AMR) is often used in the clinical setting in Japan, although there is little evidence supporting the efficacy of this. Because no study comparing PEI with Pt-Re or AMR has been performed, here, we retrospectively analyzed the efficacy of second-line chemotherapy for patients with sensitive relapsed SCLC.

\section{Patients and Methods}

We retrospectively collected data on consecutive patients with SCLC treated with second-line chemotherapy between September 2002 and December 2016 from the medical records of Shizuoka Cancer Center. The recruitment criteria for this study were as follows: 1) histologically or cytologically confirmed SCLC, 2) sensitive relapse after one previous chemoradiotherapy or chemotherapy regimen, 3) under 75 years old, and 4) no interstitial lung disease. In this study, we defined TFI as the period from the date of completion of first-line treatment to the first relapse and defined sensitive relapse as TFI $\geq 90$ days, in accordance with the definition in several previous trials $(11,13,14)$. Patients included in our study were separated into those treated with PEI (PEI group), those with Pt-Re (Pt-Re group), or those with AMR (AMR group).

We evaluated the tumor response to chemotherapy in accordance with the Response Evaluation Criteria in Solid Tumors by performing computed tomography of the chest and abdomen, magnetic resonance imaging of the head, a bone scintiscan, or positron emission tomography-computed tomography (15). All categorical variables were analyzed by $\chi^{2}$ test or Fisher's exact test, as appropriate. Clinical evaluation of progression-free survival (PFS) and overall survival (OS) after the start of second-line chemotherapy was conducted by the Kaplan-Meier method to assess the time of recurrence or death. The log-rank test was used to compare cumulative survival in each group. We assessed toxicity using the National Cancer Institute Common Toxicity Criteria, version 4.0. All $p$-values are reported as two-sided, and values $<0.05$ were considered statistically significant. Statistical analyses were performed using JMP version 9.0 (SAS Institute Inc., Cary, NC, 


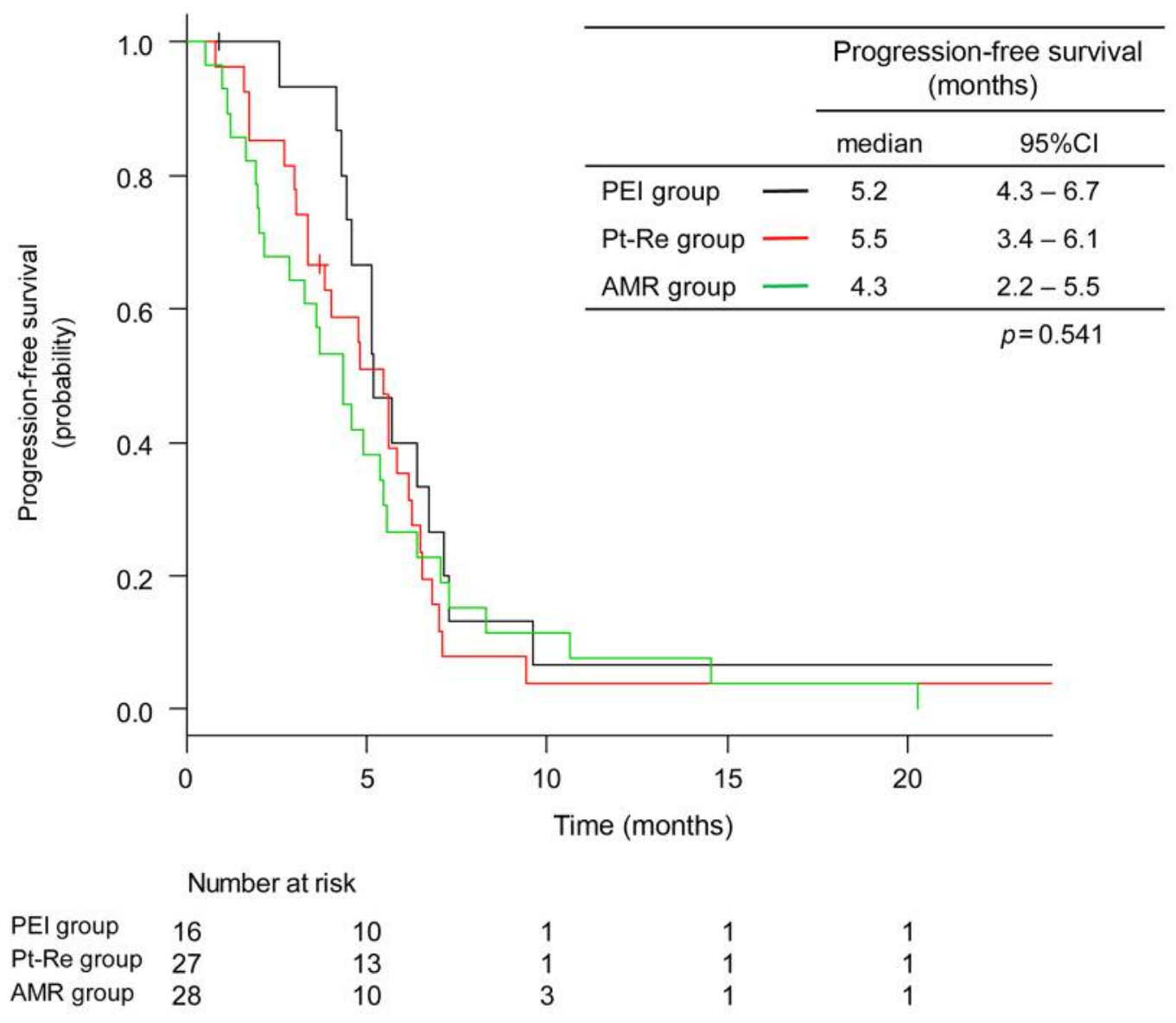

Figure 1. Progression-free survival of the three treatment groups.

USA) and EZR. Our study was approved by the Institutional Review Board of Shizuoka Cancer Center.

\section{Results}

A total of 71 SCLC patients who were treated between September 2002 and December 2016 were included in this study. Sixteen patients were included in the PEI group, 27 in the Pt-Re group, and 28 in the AMR group. The patient characteristics are listed in Table I. No significant differences in age, gender, ECOG performance status at second-line chemotherapy, smoking index, disease extent at diagnosis, response to first-line treatment, and treatment-free interval were found among the three groups.

The overall response rate was $81 \%$ in the PEI group, $48 \%$ in the Pt-Re group, and 39\% in the AMR group (Table II). There was no significant difference in overall response rate among the three groups ( $p$-value $=0.128)$. Median progressionfree survival was 5.2 months $(95 \% \mathrm{CI}=4.3-6.7$ months) in the PEI group, 5.5 months (95\%CI=3.4-6.1 months) in the Pt-Re group, and 4.3 months (95\% CI=2.2-5.5 months) in the AMR group, which did not differ significantly $(p$-value $=0.541$ ) (Figure 1). However, MST differed significantly among the three groups (23.4 months (95\% CI=11.1-28.6 months) in the PEI group, 14.2 months (95\% CI=6.4-25.6 months) in the PtRe group, and 11.5 months (95\% CI=6.7-15.4 months) in the AMR group; $p$-value $=0.047$ ) (Figure 2).

Toxicity was evaluated in all patients (Table III). The only grade 3 or worse hematological toxicity that showed a significant difference in prevalence among the three groups was thrombocytopenia (38\% in the PEI group, 37\% in the Pt-Re group, and $18 \%$ in the AMR group; $p$-value was 0.0002). There were no statistically significant differences in leukopenia, neutropenia, anemia, and febrile neutropenia. The only nonhematological toxicity of any grade was diarrhea (63\% in the PEI group, $33 \%$ in the Pt-Re group, and 14\% in the AMR group; $p$-value was 0.005$)$. There were no statistically significant differences in appetite loss, nausea, vomiting, constipation, fatigue, pneumonia, infection, AST increase, ALT increase, blood bilirubin increase, and creatinine increase among the groups. 


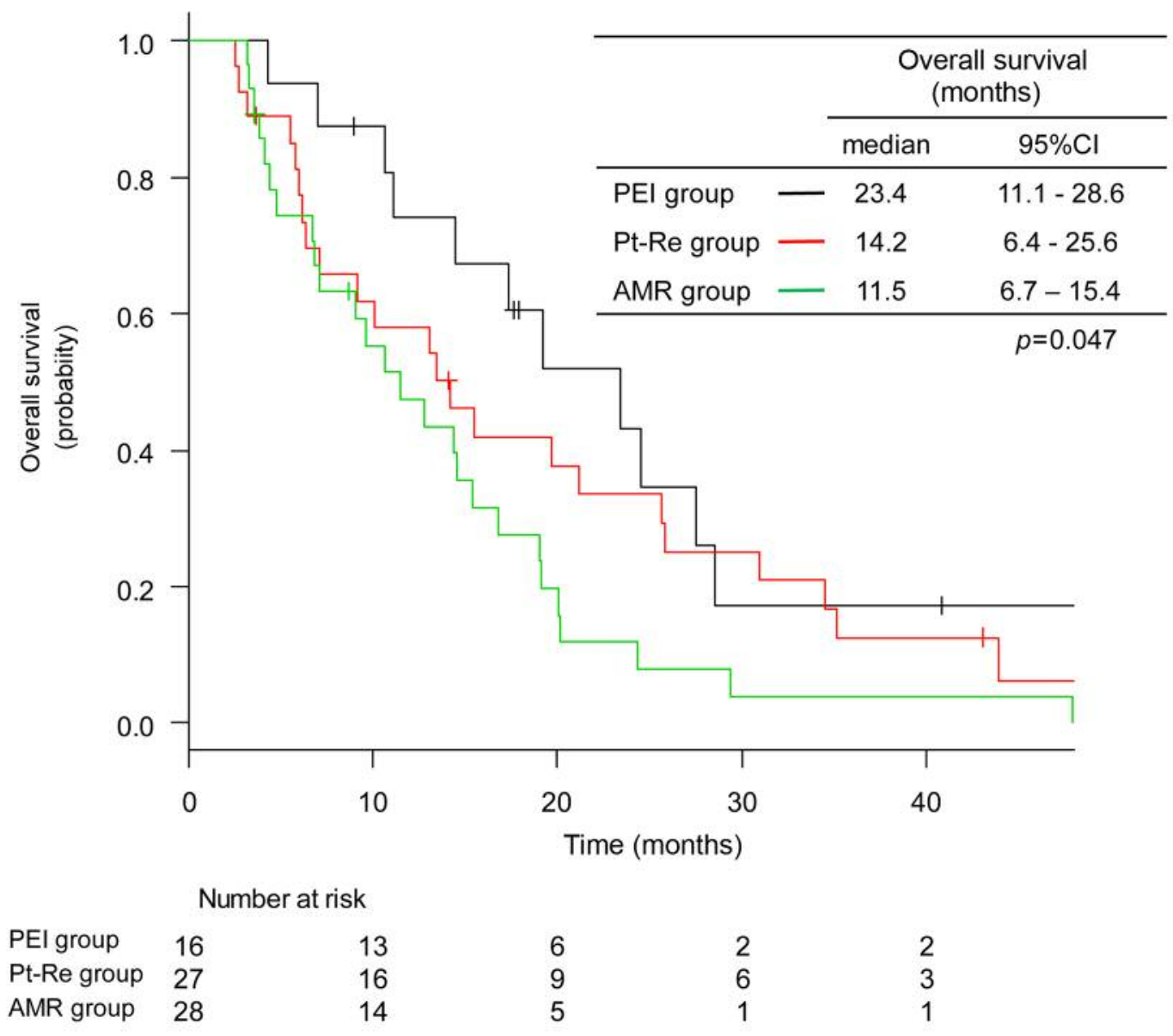

Figure 2. Overall survival of the three treatment groups.

\section{Discussion}

In this study, we retrospectively assessed the efficacy of secondline chemotherapy in patients with sensitive relapsed small-cell lung cancer. The results showed that PEI significantly prolonged survival compared with Pt-Re therapy and AMR monotherapy. Few studies assessing the efficacy of second-line chemotherapy including PEI have previously been performed.

Until recently, topotecan was the only drug showing efficacy compared with BSC and the only drug for the treatment of patients with sensitive relapsed SCLC. However, in 2016, a phase III trial comparing PEI with topotecan for patients with sensitive relapsed SCLC was reported (12). In this trial, PEI significantly prolonged overall survival compared with topotecan; however, the treatment schedule of PEI is complicated, so PEI is rarely applied in a clinical setting. Instead of PEI, Pt-Re and AMR are often used in Japan, but little evidence on their efficacy for patients with sensitive relapsed SCLC has been reported.
Few studies have assessed the efficacy of Pt-Re; the induction regimens described in previous reports were $\mathrm{CAV}$ or $\mathrm{CDE}$, which are currently not used as standard. We reported the efficacy of rechallenge chemotherapy in patients with sensitive relapsed SCLC (16). Sixty-five patients were retrospectively assessed in terms of the efficacy and adverse events. There was no significant difference in OS between the rechallenge group and the other regimen group (MST: rechallenge group, 14.4 months, other group, 13.1 months; $p=0.51)$. We thus concluded that rechallenge chemotherapy is not superior to other chemotherapies. In 2015, Genestreti et al. reported the efficacy of platinum and etoposide (17). In this report, ORR was $45 \%$ and PFS was 5.5 months. Moreover, in the same year, a randomized phase II trial (NEJ 0702) that assessed the efficacy of Pt-Re and AMR for patients with sensitive relapsed SCLC was reported (18), the primary endpoint of which was the objective response rate. In this trial, an objective response rate of $30 \%$ was set as the lower limit of interest. The results showed that the objective response rate was $67 \%$ (90\% confidence 
Table III. Adverse events associated with second-line chemotherapy.

\begin{tabular}{|c|c|c|c|c|c|c|c|}
\hline \multirow{3}{*}{$\begin{array}{l}\text { Toxicity } \\
\text { Hematological }\end{array}$} & \multirow{2}{*}{\multicolumn{2}{|c|}{$\frac{\text { PEI group }(n=16)}{\text { Grade }(n, \%)}$}} & \multirow{2}{*}{\multicolumn{2}{|c|}{$\frac{\text { Pt-Re group }(\mathrm{n}=27)}{\text { Grade }(\mathrm{n}, \%)}$}} & \multirow{2}{*}{\multicolumn{2}{|c|}{$\frac{\text { AMR group }(\mathrm{n}=28)}{\text { Grade }(\mathrm{n}, \%)}$}} & \multirow{3}{*}{$p$-Value* } \\
\hline & & & & & & & \\
\hline & Any & $\geq 3$ & Any & $\geq 3$ & Any & $\geq 3$ & \\
\hline Leukopenia & $15(94 \%)$ & $9(56 \%)$ & $26(96 \%)$ & $19(70 \%)$ & $26(93 \%)$ & $16(57 \%)$ & 0.520 \\
\hline Neutropenia & $14(88 \%)$ & $10(63 \%)$ & $26(96 \%)$ & $23(85 \%)$ & $26(93 \%)$ & $16(57 \%)$ & 0.065 \\
\hline Thrombocytopenia & $12(75 \%)$ & $6(38 \%)$ & $22(81 \%)$ & $10(37 \%)$ & $16(57 \%)$ & $5(18 \%)$ & 0.0002 \\
\hline Anemia & $16(100 \%)$ & $10(63 \%)$ & $23(85 \%)$ & $4(15 \%)$ & $22(79 \%)$ & $3(11 \%)$ & 0.218 \\
\hline \multirow[t]{2}{*}{ Febrile neutropenia } & $2(13 \%)$ & $2(13 \%)$ & $5(19 \%)$ & $5(19 \%)$ & $2(7 \%)$ & $2(7 \%)$ & 0.448 \\
\hline & \multicolumn{2}{|c|}{ Grade (n, \%) } & \multicolumn{2}{|c|}{ Grade $(\mathrm{n}, \%)$} & \multicolumn{2}{|c|}{ Grade $(\mathrm{n}, \%)$} & \\
\hline Non-hematological & Any & $\geq 2$ & Any & $\geq 2$ & Any & $\geq 2$ & \\
\hline Appetite loss & $10(63 \%)$ & $3(19 \%)$ & $17(63 \%)$ & $2(7 \%)$ & $14(50 \%)$ & $5(18 \%)$ & 0.566 \\
\hline Nausea & $5(31 \%)$ & $1(6 \%)$ & $8(30 \%)$ & $3(11 \%)$ & $7(25 \%)$ & $0(0 \%)$ & 0.886 \\
\hline Vomiting & $1(6 \%)$ & $0(0 \%)$ & $5(19 \%)$ & $1(4 \%)$ & $1(4 \%)$ & $0(0 \%)$ & 0.153 \\
\hline Diarrhea & $10(63 \%)$ & $4(25 \%)$ & $9(33 \%)$ & $1(4 \%)$ & $4(14 \%)$ & $0(0 \%)$ & 0.005 \\
\hline Constipation & $8(50 \%)$ & $1(6 \%)$ & $8(30 \%)$ & $3(11 \%)$ & $4(14 \%)$ & $1(4 \%)$ & 0.040 \\
\hline Fatigue & $7(44 \%)$ & $1(6 \%)$ & $12(44 \%)$ & $3(11 \%)$ & $9(32 \%)$ & $1(4 \%)$ & 0.600 \\
\hline Pneumonia & $0(0 \%$ & $0(0 \%)$ & $4(15 \%)$ & $4(15 \%)$ & $4(14 \%)$ & $4(14 \%)$ & 0.269 \\
\hline Infection & $2(13 \%)$ & $2(13 \%)$ & $2(7 \%)$ & $2(7 \%)$ & $2(7 \%)$ & $2(7 \%)$ & 0.803 \\
\hline AST increase & $1(6 \%)$ & $0(0 \%)$ & $3(11 \%)$ & $0(0 \%)$ & $3(11 \%)$ & $1(4 \%)$ & 0.859 \\
\hline ALT increase & $2(13 \%)$ & $1(6 \%)$ & $4(15 \%)$ & $2(7 \%)$ & $6(21 \%)$ & $1(4 \%)$ & 0.700 \\
\hline Blood bilirubin increase & $0(0 \%)$ & $0(0 \%)$ & $3(11 \%)$ & $0(0 \%)$ & $5(18 \%)$ & $1(4 \%)$ & 0.197 \\
\hline Creatinine increase & $4(25 \%)$ & $0(0 \%)$ & $6(22 \%)$ & $1(4 \%)$ & $5(18 \%)$ & $2(7 \%)$ & 0.842 \\
\hline
\end{tabular}

*Above grade 3 for hematological toxicity and any grade for non-hematological toxicity. PEI: Cisplatin, etoposide, and irinotecan combined therapy; Pt-Re: platinum rechallenge; AMR: amrubicin; AST: aspartate aminotransferase; ALT: alanine aminotransferase.

interval $=52 \%-83 \%)$ in the AMR cohort and $43 \%(90 \%$ confidence interval $=28 \%-58 \%$ ) in the Pt-Re group. Only when amrubicin was administered was the primary endpoint reached.

In the present study, we also assessed the toxicities of three regimens. The only toxicity showing a significant difference among the three groups was thrombocytopenia. Although febrile neutropenia was identified at a rate of $31.1 \%$ in the PEI group in the JCOG 0605 trial, only $13 \%$ of the PEI group developed febrile neutropenia in our study. There was no significant difference in the rate of febrile neutropenia among the three groups and $19 \%$ of the Pt-Re group developed febrile neutropenia. There was no statistically significant difference among the three groups regarding non-hematological toxicities, with the exception of diarrhea. As PEI is triplet therapy, it is associated with concerns about toxicity, but these are assuaged by the almost complete lack of significant differences in toxicity among the groups in this study.

Our study had several limitations. First, the sample size was small. However, because few studies in this field had previously been performed, we considered that the assessment of 71 patients with sensitive relapsed SCLC, including those undergoing PEI therapy as performed here, is valuable.
Second, the timing of response assessment was decided by each physician, which might have resulted in variance of ORR and PFS. Finally, we did not assess the patients' quality of life. However, there were almost no significant differences in hematological and non-hematological toxicities among the three groups.

In conclusion, this study revealed significant differences in the overall survival and that the MST of PEI was longest when comparing the three treatments. Moreover, hardly any differences in toxicities were identified among the treatments. These findings suggest that PEI should be performed in selected cases.

\section{Conflicts of Interest}

No conflicts of interest are reported by any of the Authors regarding this study.

\section{Authors' Contributions}

KW, TM, EM, NM, TK, HK, SO, KN, AO, HK, TN, HM, ME and TT contributed to treatment and data collection. KM performed the statistical analysis. 


\section{References}

1 van Meerbeeck JP, Fennell DA and De Ruysscher DK: Smallcell lung cancer. Lancet 378(9804): 1741-1755, 2011. PMID: 21565397. DOI: 10.1016/S0140-6736(11)60165-7

2 Tiseo $M$ and Ardizzoni A: Current status of second-line treatment and novel therapies for small cell lung cancer. J Thorac Oncol 2(8): 764-772, 2007. PMID: 17762346. DOI: 10.1097/JTO.0b013e3180986262

3 Rosti G, Bevilacqua G, Bidoli P, Portalone L, Santo A and Genestreti G: Small cell lung cancer. Ann Oncol 17(Suppl 2): ii5-10, 2006. PMID: 16608983. DOI: 10.1093/annonc/mdj910

4 Owonikoko TK, Behera M, Chen Z, Bhimani C, Curran WJ, Khuri FR and Ramalingam SS: A systematic analysis of efficacy of second-line chemotherapy in sensitive and refractory smallcell lung cancer. J Thorac Oncol 7(5): 866-872, 2012. PMID: 22722788. DOI: $10.1097 /$ JTO.0b013e31824c7f4b

5 Ardizzoni A, Tiseo $\mathrm{M}$ and Boni L: Validation of standard definition of sensitive versus refractory relapsed small cell lung cancer: a pooled analysis of topotecan second-line trials. Eur J Cancer 50(13): 2211-2218, 2014. PMID: 24981975. DOI: 10.1016/j.ejca.2014.06.002

6 O'Brien ME, Ciuleanu TE, Tsekov H, Shparyk Y, Cucevia B, Juhasz G, Thatcher N, Ross GA, Dane GC and Crofts T: Phase III trial comparing supportive care alone with supportive care with oral topotecan in patients with relapsed small-cell lung cancer. J Clin Oncol 24(34): 5441-5447, 2006. PMID: 17135646. DOI: $10.1200 / J C O .2006 .06 .5821$

7 Giaccone G, Ferrati P, Donadio M, Testore F and Calciati A: Reinduction chemotherapy in small cell lung cancer. Eur $\mathrm{J}$ Cancer Clin Oncol 23(11): 1697-1699, 1987. PMID: 2828074. DOI: 10.1016/0277-5379(87)90452-4

8 Postmus PE, Berendsen HH, van Zandwijk N, Splinter TA, Burghouts JT and Bakker W: Retreatment with the induction regimen in small cell lung cancer relapsing after an initial response to short term chemotherapy. Eur J Cancer Clin Oncol 23(9): 1409-1411, 1987. PMID: 2824211. DOI: 10.1016/02775379(87)90128-3

9 Inoue A, Sugawara S, Yamazaki K, Maemondo M, Suzuki T, Gomi K, Takanashi S, Inoue C, Inage M, Yokouchi $\mathrm{H}$, Watanabe H, Tsukamoto T, Saijo Y, Ishimoto O, Hommura F and Nukiwa $\mathrm{T}$ : Randomized phase II trial comparing amrubicin with topotecan in patients with previously treated small-cell lung cancer: North Japan Lung Cancer Study Group Trial 0402. J Clin Oncol 26(33): 5401-5406, 2008. PMID: 18854562 . DOI: 10.1200/JCO.2008.18.1974

10 Jotte R, Conkling P, Reynolds C, Galsky MD, Klein L, Fitzgibbons JF, McNally R, Renschler MF and Oliver JW: Randomized phase II trial of single-agent amrubicin or topotecan as second-line treatment in patients with small-cell lung cancer sensitive to firstline platinum-based chemotherapy. J Clin Oncol 29(3): 287-293, 2011. PMID: 21135284. DOI: 10.1200/JCO.2010.29.8851

11 von Pawel J, Jotte R, Spigel DR, O’Brien ME, Socinski MA, Mezger J, Steins M, Bosquee L, Bubis J, Nackaerts K, Trigo JM, Clingan P, Schutte W, Lorigan P, Reck M, Domine M, Shepherd FA, Li S and Renschler MF: Randomized phase III trial of amrubicin versus topotecan as second-line treatment for patients with small-cell lung cancer. J Clin Oncol 32(35): 4012-4019, 2014. PMID: 25385727. DOI: 10.1200/JCO.2013.54.5392
12 Goto K, Ohe Y, Shibata T, Seto T, Takahashi T, Nakagawa K, Tanaka H, Takeda K, Nishio M, Mori K, Satouchi M, Hida T, Yoshimura N, Kozuki T, Imamura F, Kiura K, Okamoto H, Sawa $\mathrm{T}$ and Tamura $\mathrm{T}$ : Combined chemotherapy with cisplatin, etoposide, and irinotecan versus topotecan alone as second-line treatment for patients with sensitive relapsed small-cell lung cancer (JCOG0605): a multicentre, open-label, randomised phase 3 trial. Lancet Oncol 17(8): 1147-1157, 2016. PMID: 27312053. DOI: $10.1016 / \mathrm{S} 1470-2045(16) 30104-8$

13 Ettinger DS, Jotte R, Lorigan P, Gupta V, Garbo L, Alemany C, Conkling P, Spigel DR, Dudek AZ, Shah C, Salgia R, McNally $\mathrm{R}$, Renschler MF and Oliver JW: Phase II study of amrubicin as second-line therapy in patients with platinum-refractory smallcell lung cancer. J Clin Oncol 28(15): 2598-2603, 2010. PMID: 20385980. DOI: 10.1200/JCO.2009.26.7682

14 Murakami H, Yamamoto N, Shibata T, Takeda K, Ichinose Y, Ohe Y, Takeda Y, Kudoh S, Atagi S, Satouchi M, Kiura K, Nogami N, Endo M, Watanabe $\mathrm{H}$ and Tamura T: A single-arm confirmatory study of amrubicin therapy in patients with refractory small-cell lung cancer: Jpn Clin Oncol Group Study (JCOG0901). Lung Cancer 84(1): 67-72, 2014. PMID: 24530204. DOI: 10.1016/j.lungcan.2014.01.012

15 Therasse P, Arbuck SG, Eisenhauer EA, Wanders J, Kaplan RS, Rubinstein L, Verweij J, Van Glabbeke M, van Oosterom AT, Christian MC and Gwyther SG: New guidelines to evaluate the response to treatment in solid tumors. European Organization for Research and Treatment of Cancer, National Cancer Institute of the United States, National Cancer Institute of Canada. J Natl Cancer Inst 92(3): 205-216, 2000. PMID: 10655437. DOI: 10.1016/S1470-2045(16)30160-7

16 Wakuda K, Kenmotsu H, Naito T, Akamatsu H, Ono A, Shukuya T, Nakamura Y, Tsuya A, Murakami H, Takahashi T, Endo M, Nakajima $\mathrm{T}$ and Yamamoto $\mathrm{N}$ : Efficacy of rechallenge chemotherapy in patients with sensitive relapsed small cell lung cancer. Am J Clin Oncol 38(1): 28-32, 2015. PMID: 23388567. DOI: $10.1097 / \mathrm{COC} .0 \mathrm{~b} 013 \mathrm{e} 318286907 \mathrm{~b}$

17 Genestreti G, Tiseo M, Kenmotsu H, Kazushige W, Di Battista M, Cavallo G, Carloni F, Bongiovanni A, Burgio MA, Casanova C, Metro G, Scarpi E, Korkmaz T, Selcuk S, Roopa K and Califano $\mathrm{R}$ : Outcomes of platinum-sensitive small-cell lung cancer patients treated with platinum/etoposide rechallenge: A multi-institutional retrospective analysis. Clin Lung Cancer 16(6): e223-228, 2015. PMID: 25983005. DOI: 10.1016/j.cllc.2015.04.006

18 Inoue A, Sugawara S, Maemondo M, Mori Y, Oizumi S, Harada M, Taima K, Morikawa N, Ishida T, Kinoshita I, Watanabe H, Suzuki T, Nakagawa T, Saito R and Nukiwa T: Randomized phase II trial comparing amrubicin with re-challenge of platinum doublet in patients with sensitive-relapsed small-cell lung cancer: North Japan Lung Cancer Study Group trial 0702. Lung Cancer 89(1): 61-65, 2015. PMID: 26004087. DOI: 10.1016/j.lungcan.2015.04.012

Received August 5, 2019 Revised September 16, 2019 Accepted September 17, 2019 